\title{
Outcome of Scalpel and Electrocautery in Abdominoplasty and Seroma Formation- A Comparative Study
}

\author{
Hemant Goyal ${ }^{1}$, Ruchika Agarwal ${ }^{2}$, Ram Avtar $^{3}$ \\ ${ }^{1}$ Assistant Professor, Department of Surgery, F.H. Medical College and Hospital, Near Railway Over Bridge, Etmadpur, Agra, India, ${ }^{2}$ Assistant Professor, \\ Department of Obstetrics and Gynaecology, F.H. Medical College and Hospital, Near Railway Over Bridge, Etmadpur, Agra, India, ${ }^{3}$ Associate Professor, \\ Department of Surgery, F.H. Medical College and Hospital, Near Railway Over Bridge, Etmadpur, Agra, India.
}

\section{Abstract}

Background: The abdominoplasty is one of the most commonly performed aesthetic surgical procedures. The present study was conducted to compare scalpel and electrocautery in abdominoplasty and its complications. Subjects and Methods: The present study was conducted on 62 patients of both genders underwent abdominoplasty. Patients were divided into 2 groups of 31 each. Group I comprised of patients in which dissection with scalpel was done and group II patients underwent abdominoplasty with electrocautery forceps. In both groups, seroma formation was recorded. Results: Males were 30 and females were 32. Seroma was seen in 6 in group I and 4 in group II. Drain output was 120.2 milliliters in group I and 82.6 milliliters in group II. The difference was significant $(\mathrm{P}<0.05)$. Conclusion: Authors found both techniques effective in abdominoplasty. Seroma was most common complication seen in both techniques.

Keywords: Abdominoplasty, Electrocautery, Seroma.

Corresponding Author: Dr. Ram Avtar, Associate Professor, Department of Surgery, F.H. Medical College and Hospital, Near Railway Over Bridge, Etmadpur, Agra, India.

Received: July 2019

Accepted: July 2019

\section{Introduction}

The abdominoplasty is one of the most commonly performed aesthetic surgical procedures across the world. ${ }^{[1]}$ It is estimated that more than 800,000 people undergo this operation each year, making it the sixth most common cosmetic procedure. The main objective of an abdominoplasty is to reshape the body contour by means of excising redundant skin and fat tissue to remodel the abdominal wall. ${ }^{[2]}$

The contemporary techniques that have subsequently been described share 3 characteristics: limited dissection of the abdominal flap, plication of the rectus abdominis fascia, and resection of a segment of skin and underlying subdermal tissue down to the scarpa fascia. Despite the popularity of abdominoplasty, patients are at significant risk of developing a complication from the procedure, the most common of which is seroma formation which occurs in around 5-30\% of patients. $^{[3]}$

The possibility of a higher incidence of seroma in lipoabdominoplasties than in abdominoplasties without liposuction remains controversial. Najera et al. ${ }^{[4]}$ published a series of 200 patients, showing that the seroma rates in the abdominoplasty and lipoabdominoplasty groups were $16 \%$ and $31.2 \%$, respectively. Seroma formation remains a significant problem in abdominoplasty surgery, the cause of which is likely to be multifactorial. Elevation of a large flap of abdominal tissue leaving two raw tissue surfaces either side of a potential space, disruption of the lymphatic drainage, hematoma formation and instruments used for tissue dissection have all been proposed as potential causes for seroma formation. Worldwide, dissection methods vary greatly between surgeons $\mathrm{e}$ in the UK the handheld electrocautery or 'Bovey' is gaining popularity whereas more senior surgeons. The present study was conducted to compare scalpel and electrocautery in abdominoplasty and its complications.

\section{Subjects and Methods}

The present study was conducted in the department of general surgery. It comprised of 62 patients of both genders underwent abdominoplasty. All were informed regarding the study and written consent was obtained. Ethical approval was taken prior to the study.

General information such as name, age, gender etc. was recorded. Patients were divided into 2 groups of 31 each. Group I comprise of patients in which dissection with scalpel was done and group II patients underwent abdominoplasty with electrocautery forceps.

In both groups the surgical technique was identical apart from the method of abdominal flap dissection. All surgery was carried out under general anaesthesia with patients marked pre operatively in a standing position. The lower incision was placed in the lowest skin crease above the pubic 
hairline and continued through onto the superficial fascia of the anterior rectus sheath.

In both groups, seroma formation was recorded. The seroma formation was defined as a fluid collection detected by palpation on clinical examination when patients attend for routine follow up clinic appointments. Results were tabulated and subjected to statistical analysis. $\mathrm{P}$ value less than 0.05 was considered significant.

\section{Result}

\begin{tabular}{|l|l|l|}
\hline Table 1: Distribution of patients \\
\hline & Group I & Group II \\
\hline Methods & Scalpel & Electrocautery \\
\hline Number & 31 & 31 \\
\hline
\end{tabular}

[Table 1] shows that group I comprise of patients in which dissection with scalpel was done and group II patients underwent abdominoplasty with electrocautery forceps. Both groups had 31 patients each.

Table 2: Gender wise distribution of patients

\begin{tabular}{|l|l|l|}
\hline Gender & Males & Females \\
\hline Number & 30 & 32 \\
\hline
\end{tabular}

[Table 2] shows that males were 30 and females were 32.

\begin{tabular}{l}
\hline Table 3: Primary outcome of treatment \\
\begin{tabular}{|l|l|l|l|}
\hline $\begin{array}{l}\text { Primary } \\
\text { outcome }\end{array}$ & Group I & Group II & P value \\
\hline Seroma & 6 & 4 & 0.01 \\
\hline $\begin{array}{l}\text { Drain output } \\
(\mathrm{mls})\end{array}$ & 120.2 & 82.6 & 0.001 \\
\hline
\end{tabular}
\end{tabular}

[Table 3] shows that seroma was seen in 6 in group I and 4 in group II. Drain output was 120.2 milliliters in group I and 82.6 milliliters in group II. The difference was significant $(\mathrm{P}<0.05)$.

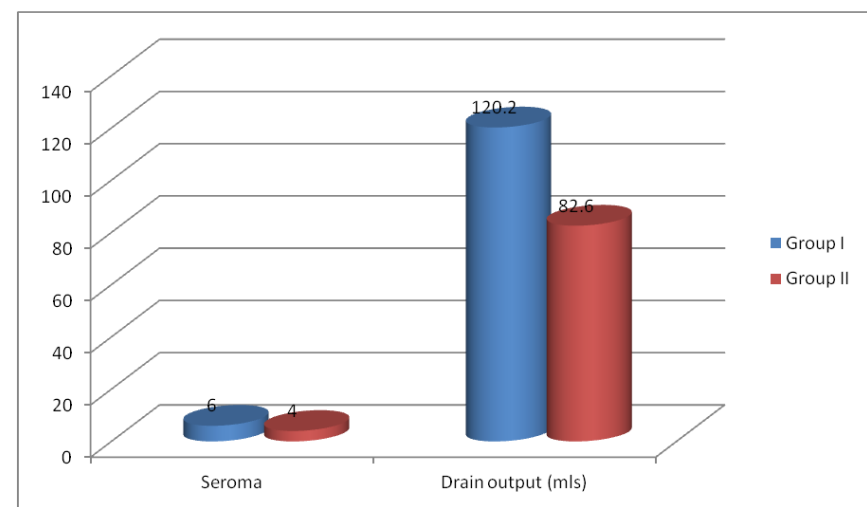

Figure 1: Primary outcome of treatment

\section{Discussion}

The appropriate patient for standard abdominoplasty has excessive, loose, sagging, abdominal skin, lax abdominal fascial wall and/or diastasis recti. Typically there is pronounced skin laxity; more than $6-8 \mathrm{~cm}$ of skin needs to be excised in the vertical dimension. Extensive undermining is necessary to provide exposure to a lax abdominal wall and to allow redraping of the skin. The muscular aponeurotic system, subcutaneous fat thickness, and skin are analyzed. Each system is addressed with the standard abdominoplasty. ${ }^{[5]}$

Swanson surveyed 497 members of the American Society of Plastic Surgeons about their preferences regarding different abdominoplasty techniques and their most frequent complications. ${ }^{[6]}$ The analysis comprised 20,029 procedures, of which $55 \%$ were traditional abdominoplasties, $35 \%$ were lipoabdominoplasties, and $10 \%$ were limited abdominoplasties, also known as mini-abdominoplasties. The local complication rates were $20 \%, 10.3 \%$, and $13.5 \%$, respectively. The systemic complication rate was less than $0.1 \%$ for all techniques. The present study was conducted to compare scalpel and electrocautery in abdominoplasty and its complications.

In present study, group I comprise of patients in which dissection with scalpel was done and group II patients underwent abdominoplasty with electrocautery forceps. Both groups had 31 patients each. Males were 30 and females were 32. Marsh et al. ${ }^{[7]}$ published a prospective randomized study comparing scalpel and handheld electrocautery dissection, finding no difference in the seroma rate between the 2 groups.

We found that seroma was seen in 6 in group I and 4 in group II. Drain output was 120.2 milliliters in group I and 82.6 milliliters in group II. Pollock and Pollock published their ex-perience with 597 patients, ${ }^{[8]}$ in whom progressive tension sutures were used for this purpose, reporting only 1 case of seroma in 12 years (Level of Evidence: Therapeutic, IV). In a similar manner, fibrin glue has also been proposed for collapsing the space below the abdominal flap.

Hensel et al, ${ }^{[9]}$ conducted a study in which primary outcome measure such as postoperative seroma formation on clinical examination, secondary outcome measures are drain volume, weight of tissue removed, effect of liposuction and patient BMI was calculated. Both study groups were similar in demographics with no significant difference in weight of tissue excised, BMI, drain output or post operative complications. There was no significant difference in seroma formation rates between the handheld electrocautery group $(17.2 \%)$ and the sharp dissection group (20.1\%). Overall, the seroma rate was $18.6 \%$. Liposuction to the flanks at the time of abdominoplasty was found to significantly increase the incidence of seroma, compared to patients having abdominoplasty alone.

Rousseau et al. ${ }^{[10]}$ retrospectively analysed 647 abdominoplasty patients which suggested that cutting diathermocoagulation use leads to an increased risk of non infective post operative fluid collection when compared to sharp dissection $(8.8 \% \mathrm{v} 4.9 \%)$. Yilmaz et al, ${ }^{[11]}$ looked at seroma formation post mastectomy and suggest electrocautery use may lead to an increase in seroma formation although numbers are small and seroma rates high in both knife and electrocautery group (37\% and $53.8 \%$ respectively). Others have found that in thyroidectomy patients use of electrocautery or scalpel for flap dissection does not significantly affect seroma formation whereas Porter et al, ${ }^{[12]}$ suggested electrocautery leads to an increase in seroma formation post mastectomy although the results were only significant at the $90 \%$ confidence interval. It may 
be from these studies on electrocautery use in mastectomy patients that the idea electrocautery causes seroma in abdominoplasty surgery may have come yet clearly a mastectomy is a very different procedure to an abdominoplasty.

\section{Conclusion}

Authors found both techniques effective in abdominoplasty. Seroma was most common complication seen in both techniques.

\section{References}

1. Baroudi R, Ferreira CA. Seroma: how to avoid it and how to treat it. Aesthet Surg J 1998;18:439-41.

2. Grazer FM. Abdominoplasty. PlastReconstrSurg 1973;51: 617-23.

3. Ousterhout DK. Combined suction-assisted lipectomy, surgical lipectomy, and surgical abdominoplasty. Ann PlastSurg 1990;24:126-32.

4. Najera RM, Asheld W, Sayeed SM, et al. Comparison of se $\neg$ romaformation following abdominoplasty with or without liposuction. Plast ReconstrSurg 2011;127:417-22.

5. Rogliani M, Silvi E, Labardi L, et al. Obese and nonobese patients: complications of abdominoplasty. Ann PlastSurg 2006;57:336-8.

6. Swanson E. Prospective outcome study of 360 patientstreat $\neg$ ed with liposuction, lipoabdominoplasty, and abdomino 7 plasty. PlastReconstrSurg 2012;129:965-78.

7. Marsh DJ, Fox A, Grobbelaar AO, et al. Abdominoplasty and seroma: a prospective randomised study comparing scalpel and handheld electrocautery dissection. J PlastRe 7 constrAesthetSurg 2015;68:192-6.

8. Pollock TA, Pollock H. Progressive tension sutures in ab $\neg$ dominoplasty: a review of 597 consecutive cases. AesthetSurg J 2012;32:729-42.

9. Hensel JM, Lehman JA Jr, Tantri MP, et al. An outcomes analysis and satisfaction survey of 199 consecutive abdominoplasties. Ann PlastSurg 2001;46:357-63.

10. Rousseau P, Vincent H, Potier B, Arnaud D, Darsonval V. Diathermocoagulation in cutting mode and large flap dissection. PlastReconstrSurg 2011; 127(5):2093-8.

11. Yilmaz KB, Dogan L, Nalbant H, et al. Comparing scalpel, electrocautery and ultrasonic dissector effects: the impact on wound complications and pro-inflammatory cytokine levels in wound fluid from mastectomy patients. J Breast Cancer 2011;14(1):58-63.

12. Porter KA, O’Connor S, Rimm E, Lopez M. Electrocautery as a factor in seroma formation following mastectomy. Am J Surg 1998; 176(1):8- 11.

Copyright: () the author(s), 2019. It is an open-access article distributed under the terms of the Creative Commons Attribution License (CC BY 4.0), which permits authors to retain ownership of the copyright for their content, and allow anyone to download, reuse, reprint, modify, distribute and/or copy the content as long as the original authors and source are cited.

How to cite this article: Goyal H, Agarwal R, Avtar R. Outcome of Scalpel and Electrocautery in Abdominoplasty and Seroma Formation- A Comparative Study. Acad. J Surg. 2019;2(2):1-6.

DOI: dx.doi.org/10.21276/ajs.2019.2.2.1 